\title{
PREPARING TECHNICAL STUDENTS TO BE EFFECTIVE MEETING PARTICIPANTS-- SOME TEACHING TECHNIQUES
}

\author{
Ron S. Buco
}

\begin{abstract}
Teaching technical students how to participate in department meetings should be an essential component of "Communication" courses taught in undergraduate Engineering and two-year Engineering Technology programs. To date, most "Meetings" instruction has concentrated on how to chair a meeting, whereas the emphasis should be placed on how to take part in meetings and how to present information, for this is what most engineers and technologists do at the meetings they attend during the initial years following graduation.
\end{abstract}

\section{Introduction}

The subject "Technical Communication and Report Writing" taught to two-year technology students at Red River Community College in Winnipeg includes a significant component on oral communication. In turn, this component is divided into several segments, one of which is "Meetings." For 15 years the major emphasis I placed on this segment was to teach how to run (i.e. chair) a successful meeting, and I concluded my instruction by screening John Cleese's humorous film Meetings Bloody Meetings. My students sat dutifully through my teaching but loved the film.

Five years ago, following a discussion with graduates, I discovered that they felt the information I gave them was useful but in effect few if any of them used it. And those that did-mostly graduates of several years--said that by the time they actually chaired meetings they had forgotten most of what I had taught. They suggested I would do better to teach how to take part in meetings, because that was what they did at any meetings they attended.

So I revamped my course and made it more interactive, devising scenarios in which groups of students could role-play different roles they might encounter in business or industry. This paper describes my approach, the case studies I developed to create the scenarios, and a videotape I 
subsequently made on taking part in meetings, to complement John Cleese's film.

\section{The Instruction}

The instructional part of the "Meetings" segment lasts one hour. I start by outlining the three types of people who attend meetings (the chairperson, the participants, and the secretary) and point out that, as the participants are in the majority, they can do most to improve meeting effectiveness. I also dispel a preconceived impression that 'the secretary' is someone from the secretarial pool, and show that they, as meeting participants, on occasion are likely to be asked to record minutes.

I spend a few minutes outlining the chairperson's role, concentrating on the need to prepare and distribute an agenda 48 hours before a meeting is scheduled to take place. Arrival of the agenda then provides the prompt for the participants to start preparing for the meeting.

The participants's role I divide into two parts: preparation before the meeting, and conduct during the meeting. In the preparation stage I suggest that if they have to present information they divide it into three compartments:

1. What they most need to tell their audience (their "Main Message").

2. The essential information they need to present to support their Main Message (the "Need to Know" details).

3. Facts and figures they only might be asked about, which they should hold in reserve (the "Nice to Know" details).

During the meeting I suggest that they:

- Arrive on time, and come prepared.

- Present information coherently.

- Speak only when they have something useful to contribute.

- Catch the chairperson's eye before speaking.

- Address the chairperson primarily.

- Avoid holding private conversations (asides).

- Use body language to hold attention.

I include suggestions for recordings and writing the minutes, and end the first hour by screening the videotape Taking Part in Office Meetings. 


\section{The Videotape}

Rather than instruct directly, the videotape conveys its message as a dramatic vignette. It features an employee who has prepared a proposal for purchasing portable computers and wants it presented to the budget committee. Normally the department head would attend the meeting and present the proposal, but is to be out of town and so delegates the task to the employee and offers some pointers. In doing so, the department head refers to good and bad things that have been done at previous meetings, and we see examples as flashbacks.

Ten days later the employee attends the meeting, presents the proposal extremely well, and deals confidently with people who oppose the idea. After some deliberation the committee approves a modified request.

\section{The Case Studies}

At this point I issue one of four case studies, each of which calls for six to nine participants. The case studies are:

1. "Allocating Renovation Funds," in which section heads meet to present their reasons for wanting special funds allocated to the sections they represent.

2. "Increasing the Effectiveness of Business Meetings," in which staff are asked to present their ideas on how meetings can be speeded up.

3. "Choosing a Commemorative Event," in which participants are asked to recommend a social event for the company's 25 th anniversary.

4. "Approving Staff Development Requests," in which members of the staff development committee have to approve or reject requests for funds from a limited budget.

Each case study contains comprehensive printed sheets for the participants, comprising: a general description of the scenario, which everyone receives; and individual descriptions of each participant's particular role, which only he or she is privy to. The general description outlines the situation and the people involved (an example drawn from the "Renovation Funds" case study is included on page 52), and indicates that there is likely to be a problem in getting agreement during the meeting. For instance, students taking part in the "Requests for Renovation Funds" meeting are warned that previous requests have exceeded the available funds, and during their meeting they find the same has happened, to the tune of $\$ 8500$. 
The individual scenarios are more specific. Each describes the participant's role within the company and what he or she wants to achieve or obtain approval for during the meeting, and why (for an example from the same case study, see page 53). Many also prepare the participant to expect personality conflicts to occur and even warn him or her to be wary of certain individuals. For instance, the instructions for the Manager of Research and Development in the Renovations Funds case study contain a comment that ". . you expect most opposition to come from the Supervisor of Purchasing and Supply, who always comes in with heavy, competitive demands."

Some of the role descriptions contain supportive data, ranging from a one-page noise level report for a department supervisor who is requesting installation of sound-proofing, to a manufacturer's brochure describing a nonskid floor paint called RIDSKID that the Production Supervisor wants to apply to the shop floor. Additionally, the participants are encouraged to improvise background details that will make their requests seem more authentic.

Although I should assign roles to students randomly, I tend to issue certain key roles to individuals who I am reasonably sure will do them justice. (A misfit in the chairperson's shoes, for instance, could irretrievably damage the leaming experience for all the students taking part in the meeting.) As an example, an outspoken, fairly aggressive person is needed to handle one of the roles in the "Improving Meetings" case study, because the scenario tells him or her that:

\section{YOUR VIEWS ARE CONTRARY TO THE PURPOSE OF THE MEETING!}

You believe very strongly that meetings should provide an open forum for discussion. They should "free-wheel," so that participants are encouraged to speak up and never feel inhibited to present their ideas.

The students are given ample time to prepare their roles (normally they are issued during one class for a meeting to be held at the next) and are encouraged to discuss their strategies with me. Six to nine more students are asked to observe particular meeting members on a one-to-one basis, and are given specific competencies to assess and comment on after the meeting. (See the observer's comment sheet on page 54.) 
I find the most difficult part of the meeting is just sitting on the sidelines and allowing it to progress in whatever direction the chairperson and the participants choose to take it. Before the meeting I tell the students that I expect the meeting to last between 30 and 40 minutes, that it is entirely in their hands, and that I will not intercede unless they come to blows! (Only once have I had to step in, and this was in a business setting where I unwittingly assigned arch enemies to protagonist roles.)

The discussion following each meeting, with the observers often more critical than I might have been, is an important part of the learning process for both the meeting participants and the observers. The students relax, laugh at their goofs and foibles, and ask what they should have done to cope with the awkward situations that arose. Frequently, the answers are offered not by me, but by other students.

Depending on the group and the time available, after the mock meeting is over (or meetings, if it is a large class and we hold more than one) I also present John Cleese's film Meetings Bloody Meetings, partly to demonstrate to the students what their eventual responsibilities will be as a meeting manager, and partly to provide an entertaining change of pace.

\section{Conclusion}

Students seem to learn much more in the "Meetings" segment of their Communication and Report Writing program now that the emphasis has shifted from their role as a possible meeting manager to the more likely role of meeting participant. The introduction of role-playing within the framework of realistic case studies has increased their understanding of office business meetings and how they will be expected to participate.

Ron Blicq is Head, Technology Communication Department, Red River Community College, Winnipeg. 


\section{VANCOUAT ELSINESS SYSTEMSINC. MEETING TO ALLOCATE RENOVATION FUNDS}

Vancourt Business Systems Inc is a medium sized company with about 400 employees involved in the design, development, production, marketing, and servicing of a wide range of business systems, many utilizing computer and micro-electronic techniques. The company has other plants in North America and worldwide, each specializing in a particular type of product or service.

Your plant's primary customers are local businesses, government organizations, and the military, all of whom use Vancourt systems.

It is nearing the end of the financial year, and the Renovations Budget still has $\$ 34,000$ in hand.

Every year at this time the company Vice President calls a meeting to identify which departments need renovation work done, and to distribute the remaining funds equitably among them. He asks department heads to come to the meeting with their requests in hand. In previous years the requests have far exceeded the available funds. The same is likely to happen this year.

Persons who will be attending the meeting (and the number of persons in their departments) are:

Vice President

Supervisor, Office Services (32)

Manager, Research \& Development (35)

Production Supervisor (160)

Supervisor, Purchasing \& Supply (34)

Manager, Marketing \& Customer Service (60)

Personnel Administrator (6)

Test Lab Supervisor (4)

\section{THE EXERCISE}

The purpose of the exercise is to provide participants with an opportunity to organize and present information at a meeting, to ask questions, and to respond to questions.

There is unlikely to be sufficient time for funds to be assigned during the meeting, although some preliminary conclusions should become apparent.

\section{PROCEDURE}

- Department Heads will present their requests.

- Other meeting participants will question (challenge?) their requests.

- After the meeting, observers will comment on the effectiveness of the participants' presentations.

REFER TO A SEPARATE SHEET FOR A DESCRIPTION OF YOUR ROLE AT THE MEETING. 


\section{TEST LAB SUPERVISOR}

As TEST LAB SUPERVISOR at Vancourt Business Systems Inc you are responsible for a small range of Standards, and for all testing that is done in the plant. Four persons work in the Lab with you.

You have been asked by the company Vice President to attend a meeting to allocate renovation funds. (Refer to a separate sheet for more information on the company and the renovations budget.)

You come to the meeting planning to:

- Ask for $\$ 1600$ to repair and repaint the cleaning room attached to the Test Lab.

Water ingress caused by rain seeping through a damaged roof has caused unsightly damage. The damage has not harmed any equipment and does not affect your operations (the roof has since been repaired), but you are concerned that the Department of Communications inspection team may make a negative observation during their next inspection, in three months.

You cannot afford to have any unnecessary negative comments because your Lab is only just within acceptable DOC standards.

You may insert additional ideas of your own to strengthen your request.

You resent the inflated claims always made by Purchasing/Supply and Research \& Development for what you consider to be "frills" (renovations which are nice to have but are not really necessary - they don't add to the quality of the company's products and services). You believe the company can operate just as effectively without the expensive changes these two departments always seem to want - and get! 


\section{OBSERVER}

\section{MEETING TO ALLOCATE RENOVATION FUNDS}

As a meeting observer, you are to comment on the presentation made by the (Refer to a separate sheet for descriptions of the circumstances and the persons taking part in the meeting.)

Points you should particularly note are:

1. Does he/she open with a SUMMARY?

2. Does he/she document facts logically and clearly, and do they support the summary?

3. Overall, does he/she make an effective, well-organized presentation?

Make notes here: 